\title{
Laser Beam Melting of Complexly Shaped Honeycomb Structures
}

\author{
M. Binder ${ }^{1)}$, M. Illgner2), G. Schlick ${ }^{3)}$, C. Seidel(4), G. Reinhart ${ }^{5)}$
}

1) Fraunhofer IGCV, maximilian.binder@igcv.fraunhofer.de, Beim Glaspalast 5, 86153 Augsburg, Germany

2) Fraunhofer IGCV, matthias.illgner@igcv.fraunhofer.de, Beim Glaspalast 5, 86153 Augsburg, Germany

3) Fraunhofer IGCV, georg.schlick@igcv.fraunhofer.de, Beim Glaspalast 5, 86153 Augsburg, Germany

4) Fraunhofer IGCV, christian.seidel@igcv.fraunhofer.de, Beim Glaspalast 5, 86153 Augsburg, Germany

5) Fraunhofer IGCV, gunther.reinhart@igcv.fraunhofer.de, Beim Glaspalast 5, 86153 Augsburg, Germany

\section{Keywords}

additive manufacturing, AISi10Mg, composite core material, freeform surface, laser beam melting, lightweight, load oriented structure, metallic honeycombs, powder bed fusion, selective laser melting

\begin{abstract}
Laser beam melting (LBM) offers the opportunity to manufacture highly complex structures and geometries and thus provides a big potential to produce lightweight parts. In previous research projects, a software tool has been developed that achieves the placement of hexagonal honeycombs on free formed surfaces in a load-oriented manner and thus offers new possibilities for designing lightweight components (e.g. [1-2]).

This work examines the production of metal hexagonal honeycombs made from AISi10Mg with the LBMprocess. By adapting the exposure and process parameters, it was possible to manufacture overhanging structures with an overhang angel of $<30^{\circ}$ without support structures, while still achieving an acceptable surface roughness. Conventional complex and time consuming post-processing steps can thus be avoided and a higher utilization of building space can be achieved. Furthermore, since the critical size for a lightweight structure is the minimum possible weight bearing a specific load, it was investigated to which minimum values the wall thicknesses of the hexagonal structures can be reduced using LBM. The stability of the manufactured honeycombs was analyzed in as-built conditions and heat treated in reference to their density. Finally the additively manufactured honeycombs are compared to conventionally manufactured ones.
\end{abstract}

\section{Introduction}

In today's product development, it is of interest to design lighter components, without loss of stability. Lightweight structures can lead to higher performances of accelerated components and to material savings. In order to shape geometries as lightly as possible, cellular materials are frequently used. However, hardly any lightweight cellular structure reaches the properties of the honeycomb structure, which convinces with its density and excellent mechanical properties. [3-4]

Most metal honeycomb structures used in lightweight applications today are produced from sheet metal by sheet metal forming or expansion [4]. Therefore, the half-finished product has the shape of a simple 
bar or plate. When producing a complex freeform shape, these honeycomb structures are of limited use. They frequently need to be bent or cut, which reduces the stability of the sandwich core.

Additive manufacturing (i.e. Laser Beam Melting "LBM" as part of process category Powder Bed Fusion) allows the production of highly complex parts with very few limitations. Laser Beam Melting builds up a part layer by layer in a powder bed using a laser to solidify the defined areas in each layer. To overcome the mentioned limitations of conventionally manufactured honeycomb core materials it is examined how Laser Beam Melting can build complexly shaped honeycomb structures.

The present investigation is divided into three steps: At first a market analysis is carried out to show the commonly used parameters of conventionally manufactured honeycombs (e.g. cell size and wall thickness). The second step is a feasibility study which aims to build up a honeycomb structure by LBM. Three different specimens are used to determine a parameter set that enables a LBM-build honeycomb. In the third step, the LBM-built honeycomb is tested with a stabilized pressure test according to ASTM C365 and the results are compared to conventionally manufactured honeycombs. Figure 1 shows the development of the LBM honeycomb structure. This work mainly represents the feasibility study and the mechanical properties. Results from the market analysis are presented as benchmark for the mechanical properties of LBM-made honeycomb structures.

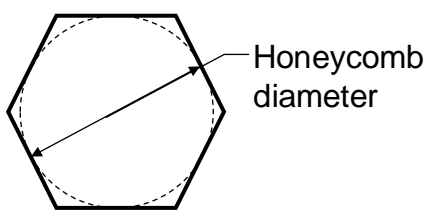

Figure 1: Definition of the honeycomb diameter in this study.

\section{Materials and methods}

The material for all examinations was aluminum alloy AISi10Mg. Laser beam melting experiments were conducted on a SLM $125 \mathrm{HL}$ machine provided from SLM Solutions. The machine is part of the additive manufacturing laboratory (AMLab) at Fraunhofer IGCV in Augsburg. The machine uses a 400 Watt fibre laser with a $70 \mu \mathrm{m}$ focus spot. The built envelope measures $125 \times 125 \times 125 \mathrm{~mm}^{3}$. The layer thickness used for all experiments was $50 \mu \mathrm{m}$.

\subsection{Feasibility Study - Laser beam melting of thin overhanging structures}

For the assessment of the manufacturability of honeycomb-like structures, different manufacturing experiments were conducted.

The aim of the first set of experiments was to increase the buildable overhang without the need to use support structures. Thin plates were built with a connection to a central rod. The design of these specimens is shown together with the built specimens in figure 2. Subsequently, this specimen design is called flower-specimen. These structures were used in order to assess the manufacturability of different overhang angles, the resulting surface quality, the minimal reachable wall thickness for overhang structures and the length of the overhanging structure. 

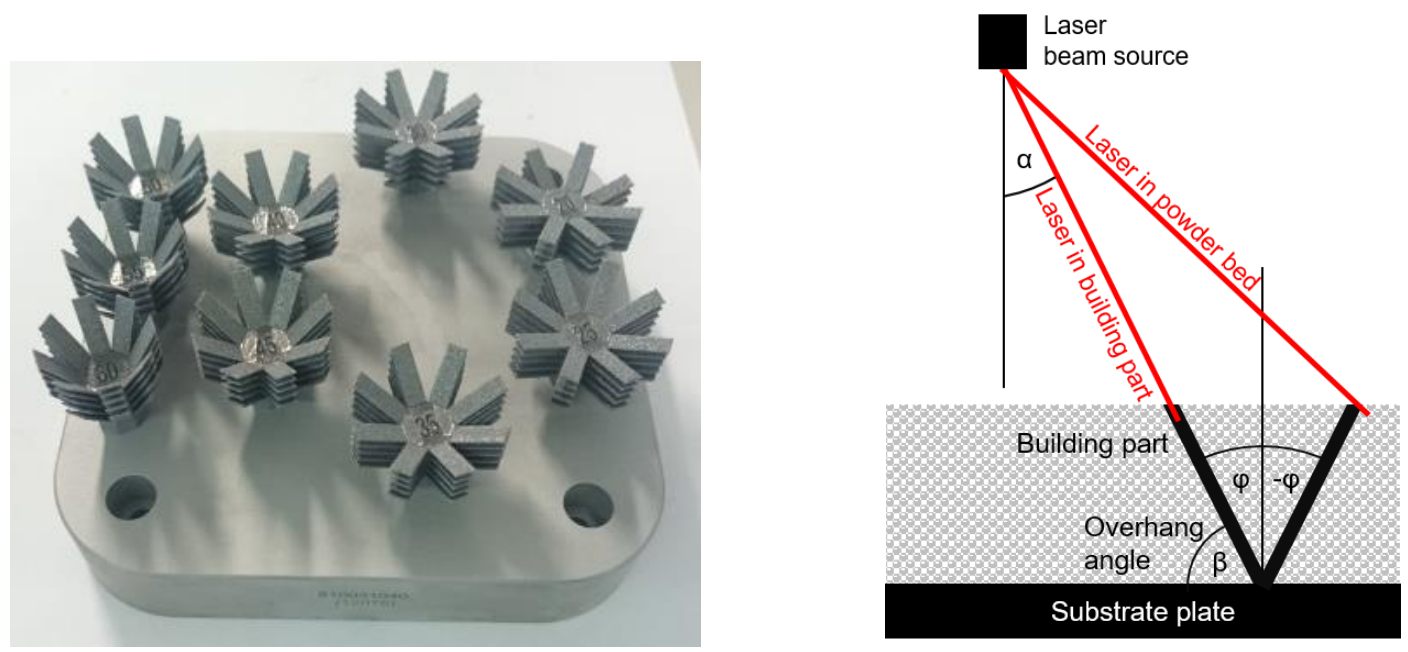

Figure 2: First experimental setup. Thin platelets connected to a central rod (flower-specimen). In this experiment different overhang angles as well as different platelet thicknesses can be analyzed. Picture of built-up specimen (left) and orientation of the platelets to the laser beam (right).

The first experimental setup was conducted for a broad range of nominal platelet thicknesses and overhang angles $(\beta)$. Details about the used parameters can be taken from table 1 . The arrangement of the platelets also gives the opportunity to assess the influence of the overhang orientation compared to the laser beam and the coating and gas flow direction. The right part of figure 2 shows the variation of the angle to the laser beam between different platelets of one flower-specimen.

Table 1: Used parameters for the first experimental setup ("flower-specimen")

\begin{tabular}{|l|l|l|}
\hline Parameter & Parameter range & Step size \\
\hline Nominal platelet thickness & $0.1-0.5 \mathrm{~mm}$ & $0.1 \mathrm{~mm}$ \\
\hline Overhang angle & $60^{\circ}-20^{\circ}$ & $5^{\circ}$ \\
\hline
\end{tabular}

Based on the results of these structures the specimen geometry was changed and the number of parameters was reduced. The second experimental setup aims towards minimization of the built platelet thickness. Thus, a specimen structure similar to a honeycomb structure was built with the aim of manufacturing the minimal possible honeycomb wall thickness under a honeycomb-typical overhang angle of $30^{\circ}$. For its similarity to a house like structure these specimens are subsequently called roofspecimen. Figure 3 shows several built up roof specimens.

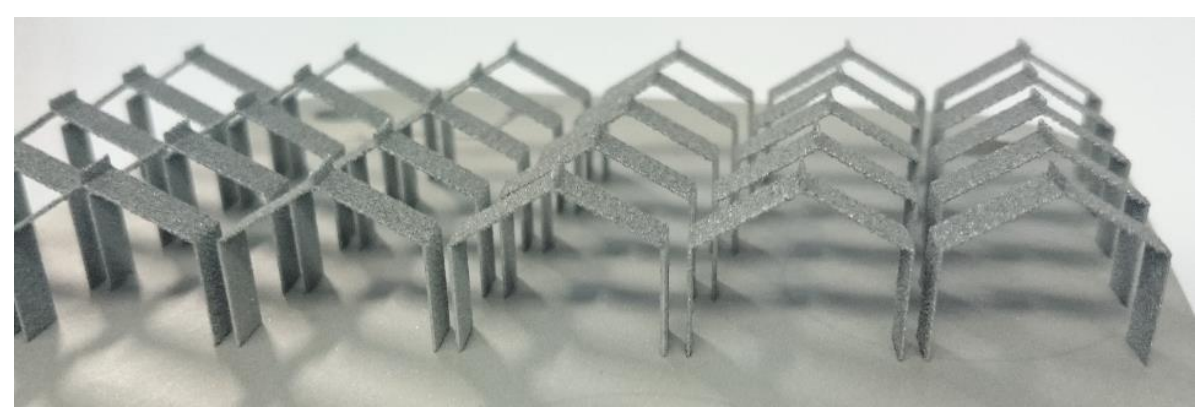

Figure 3: Second experimental setup. Built up roof-specimens.

Within this experimental setup the main attention was given to finding laser parameters for the minimal reachable wall thickness. The laser parameters used and the specimen orientation in the build chamber can be seen in figure 4. For the roof specimen special attention was given to the scanning strategy. No 
hatching is used and the walls consist of only one laser line which is scanned twice. Due to a limitation of the preparation software scanning the laser lines only once is not possible.

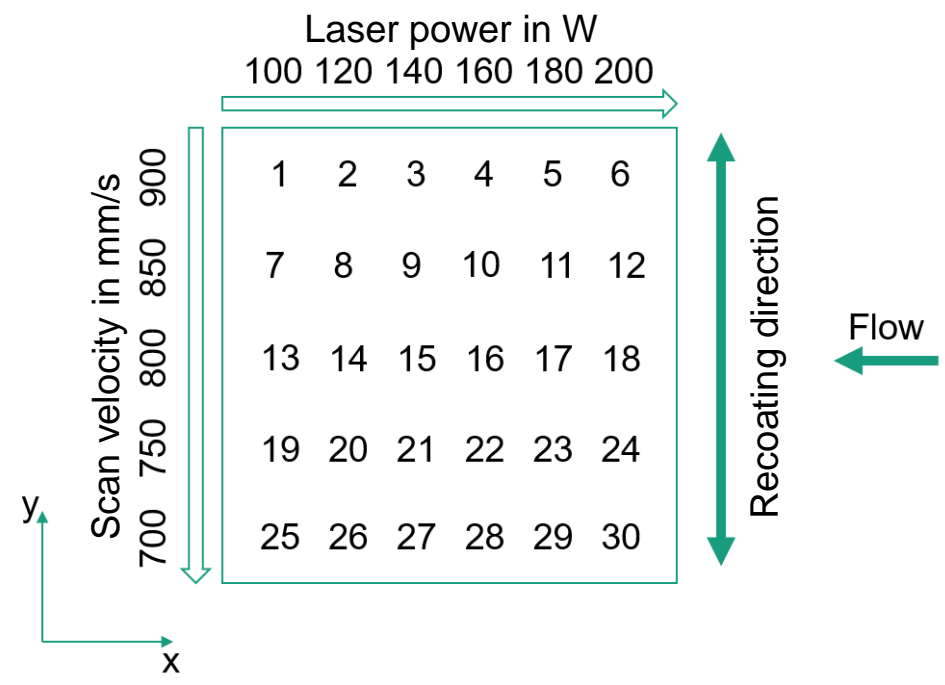

Figure 4: Laser parameters and specimen orientation used for the second experimental setup (excerpt from the full experimental design).

\subsection{Mechanical properties - Compressive strength of honeycomb specimen}

In order to analyze the structural integrity of additively manufactured honeycomb structures stabilized compressive tests (according to ASTM C365) were conducted. Within this test different orientations in the build chamber as well as different build heights and different heat treatments were analyzed using a DoE-study. The built specimens can be seen in figure 5 (right) and the DoE-parameters can be seen in figure 5 (left). Based on the prior investigations the laser parameters where chosen as $150 \mathrm{~W}$ and $500 \mathrm{~mm} / \mathrm{s}$. These parameters lead to a honeycomb wall thickness of approximately $0.60 \mathrm{~mm}$ and a stable honeycomb structure.

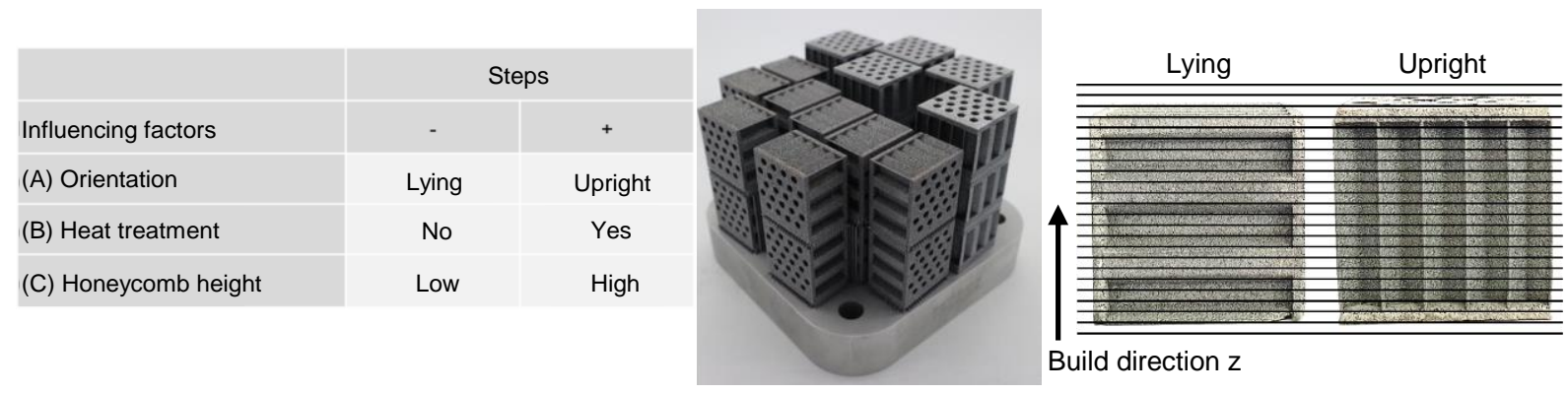

Figure 5: DoE-parameters for compression testing. The figures show the built specimens on the platform (mid) and in their layer-structure (right, not true to scale)

The parameter orientation (A) covers two perpendicular cases. The orientation of the honeycomb structure is horizontal or lying within the built cahmber (perpendicular to building direction Z) or upright (parallel to building direction Z). The horizontal orientation can be seen in figure 5 on the left side of the picture the upright orientation on the right. The height of the specimen is $15.9 \mathrm{~mm}$ (low) and $25 \mathrm{~mm}$ (high). Based on the market research performed within this work, the honeycomb diameter of all specimen was set to be $6.4 \mathrm{~mm}$ because this is a widely used value in the industrial environment.

To allow the investigation of more specimen and thereby a broader variation of parameters the specimen's base area was reduced in comparison to standard ASTM-C365-specimen. With a small amount of full-size specimen, a scale factor is obtained to convert the results to the ASTM-specimen specifications.

Figure 6 shows the time-temperature-profile of the heat treatment cycle, which is recommended by EOS for aluminum [5]. After heating up, the part is held at a temperature of $300^{\circ} \mathrm{C}$ for 2 hours. The total time 
for the cycle is approximately 20 hours. Due to the maximum temperature of $300{ }^{\circ} \mathrm{C}$, an oxidation of the part is unlikely and no shielding gas was used. The heat treatments were conducted in an oven of type $\mathrm{N} 31 / \mathrm{H}$ by Nabertherm.

Compressive tests were conducted on an Inspekt 250 by Hegewald \& Peschke. The force was applied with a velocity of $0.5 \mathrm{~mm} / \mathrm{min}$.

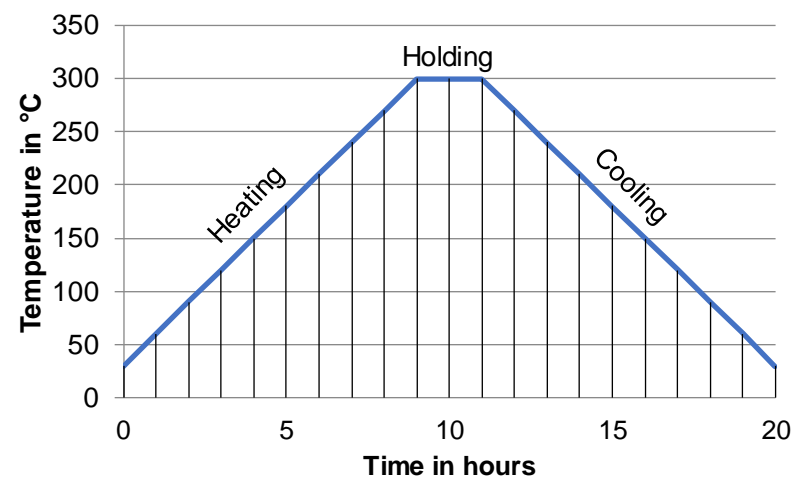

Figure 6: EOS recommended heat treatment cycle for LBM-manufactured Aluminum [5].

\section{Results}

\subsection{Feasibility Study - Laser beam melting of thin overhanging structures}

Through the investigation of the flower-specimen, several important parameters for the manufacturability of thin overhanging structures were identified. Table 2 gives a summary on considered parameters and a short result notice.

Table 2: Results for the manufacturability of thin overhanging structures ("flower-specimen")

\begin{tabular}{|c|c|}
\hline Parameter & Result \\
\hline Wall thickness & See discussion below \\
\hline Overhang angle & See discussion below \\
\hline Surface quality (i.e. roughness) & $\begin{array}{l}\text { Up-Skin (Surface orientation to laser beam): } \\
\text { Independent from overhang angle, Ra } \sim 20 \mu \mathrm{m} \\
\text { Down-Skin (Surface orientation to powder bed): } \\
\text { Lower roughness with raising angle, } \\
\text { Ra } 45 \mu \mathrm{m} \text { for an overhang angle of } 20^{\circ}, \text { Ra } 20 \mu \mathrm{m} \\
\text { for an overhang angle of } 60^{\circ}\end{array}$ \\
\hline Length of overhanging platelet & $\begin{array}{l}\text { All specimen were built with a length of } 12 \mathrm{~mm} \\
\text { without any occurring problems. Hence, } \\
\text { honeycombs with a honeycomb diameter of } \\
\text { approximately } 24 \mathrm{~mm} \text { can be assumed to be } \\
\text { buildable. }\end{array}$ \\
\hline Orientation to laser beam & $\begin{array}{l}\text { The orientation to the laser beam (see figure } 2 \text { ) has } \\
\text { an influence on the thickness of the platelet. } \\
\text { Summarized for all angles the platelets built up in } \\
\text { the direction of the laser beam are } \sim 7 \% \text { thinner than } \\
\text { the other ones. }\end{array}$ \\
\hline Orientation to coater and shielding gas flow & $\begin{array}{l}\text { No impact detected. The SLM } 125 \mathrm{HL} \text { machine was } \\
\text { equipped with a silicon coater blade. The shielding } \\
\text { gas flow was according to SLM-standard as of the } \\
\text { year } 2015 \text {. }\end{array}$ \\
\hline
\end{tabular}


Figure 7 shows the obtained plate thickness (Y-axis) against the overhang angle (X-axis). It can be seen that with a higher overhang angle the thickness of the plates is reduced. Nevertheless, the obtained thickness is much higher than the CAD-defined wall thickness (nominal thickness). For example at an overhang angle of $20^{\circ}$ and a nominal thickness of $0.1 \mathrm{~mm}$ the obtained thickness of the platelet is 0.61 $\mathrm{mm}$, which is a deviation in excess of $500 \%$ from the CAD-defined wall thickness. It is also shown that there is a limitation in wall thickness with the parameter set utilized for the LBM-process at $0.5-0.6 \mathrm{~mm}$ thickness. No built wall thickness within this study was thinner than $0.5 \mathrm{~mm}$, although the CAD-defined wall thickness starts at $0.1 \mathrm{~mm}$.

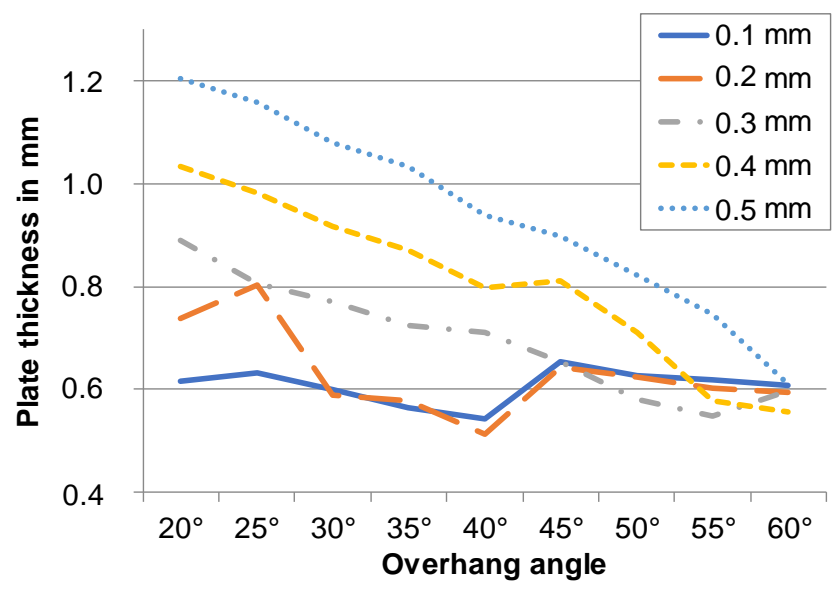

Figure 7: Reachable wall thickness for different overhang angles and different nominal wall thicknesses.

The significant increase of the wall thickness between $40^{\circ}$ and $45^{\circ}$, especially for the thin nominal thicknesses, has a software-based reason. At an angle of $43^{\circ}$ the preparation software switches the type of light exposure setting to a special parameter set for overhanging surfaces. This leads to an increase in in wall thickness. This effect occurs also for the other specimens, but the impact is not as distinctive.

The findings of this first step, investigating the general feasibility of thin overhanging structures with LBM, show that thin overhanging structures can be manufactured with LBM. However, the wall thickness of the obtained platelets is never thinner than $0.5 \mathrm{~mm}$ and shows up to a $500 \%$ deviation to the CADdefined wall thickness. This might also be of relevance for cost calculation tools and should either be considered through design rules, which ensure that no wall thickness is below $0.5 \mathrm{~mm}$ or by specific overhead factors. Obviously, this deviation in thickness does also lead to an increase in part mass, which might be relevant at several points of the parts life cycle.

To obtain thinner wall thicknesses an optimization of the light exposure parameters for the LBM process was carried out by utilizing the roof-specimen. Here, special attention was given to the scanning strategy. In Figure 8, the reachable wall thickness of structures with an overhanging angle of $30^{\circ}$ is plotted against the used laser power and the scan velocity. It can be seen, that a wall thickness down to approximately $0.35 \mathrm{~mm}$ was achievable. However below $0.45 \mathrm{~mm}$ the walls of the honeycombs tend to have pores and are therefore not as stable as honeycombs with a higher wall thickness. Some of the very thin walls were even damaged during unpacking and handling. 


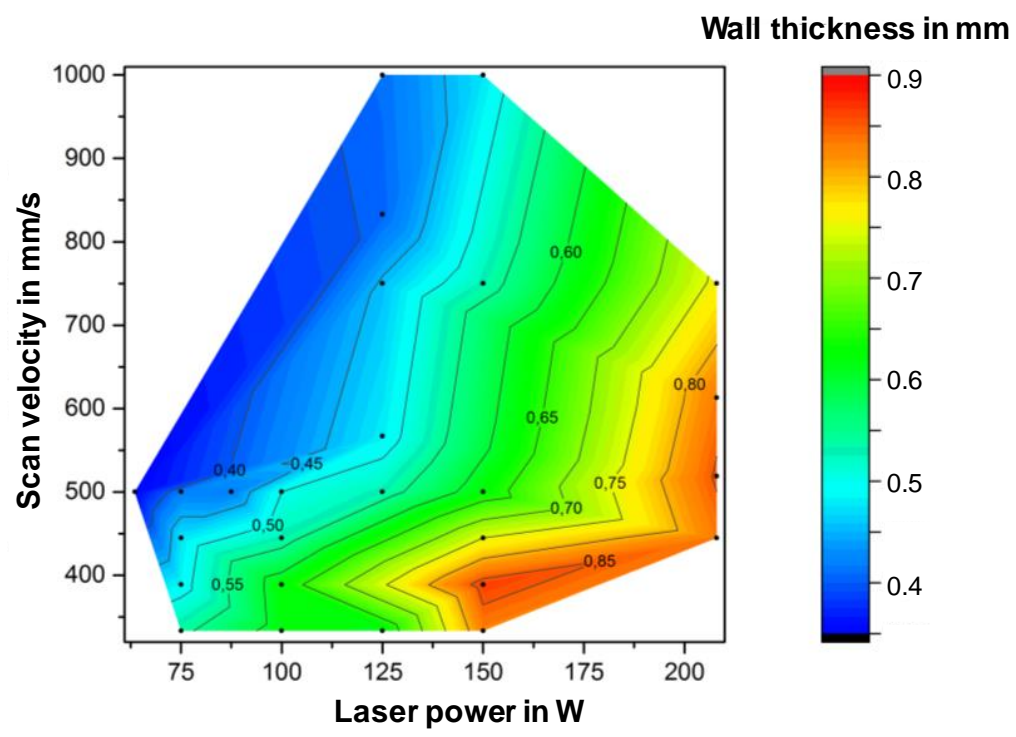

Figure 8: Reachable wall thickness for overhanging $\left(30^{\circ}\right)$ structures using different laser power and scanning speeds.

\subsection{Mechanical properties - Compressive strength of honeycomb specimen}

In figure 9, the compressive strength of different conventionally manufactured alloys is plotted against the honeycomb density. The market analysis shows that there is a linear dependency between the density of the honeycomb structure and the compressive strength (trend lines in figure 9 ). Conventionally manufactured honeycomb structures made from 3xxx-Alloys are marked as blue dots, whereas 5xxxAlloys are marked with orange crosses. Included in this diagram are also the samples built by laser beam melting within this study.

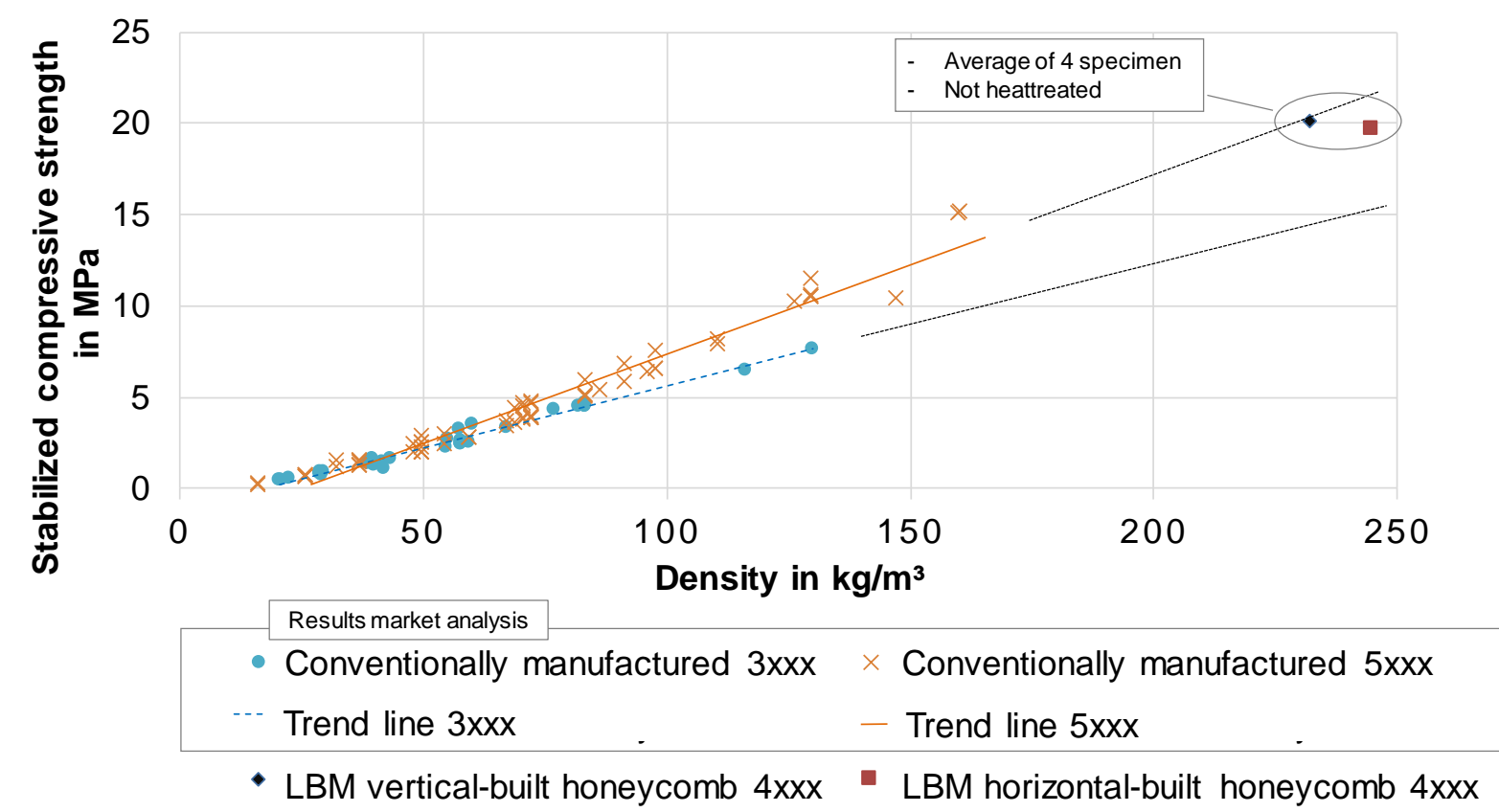

Figure 9: Stabilized compressive strength of conventionally manufactured honeycombs compared to honeycombs manufactured by laser beam melting [6-14].

Most of the conventionally manufactured honeycombs are either made from aluminum of the $3 x x x-$ or the $5 x x x$-series while the alloy used for the LBM-process AISi10Mg is an alloy from the $4 x x x$-series. Therefore, the results are not entirely comparable. However, it can still be seen, that honeycombs 
manufactured by means of laser beam melting have a similar strength-to-density-ratio as conventionally manufactured ones. Also the plotted values are in as-built condition.

The DoE effect diagrams (figure 10) show that the heat treatment has a major effect on the stabilized compressive strength of the honeycombs. In this case the heat treatment reduces the compressive strength. This mainly shows that the used heat treatment is not optimal for the material at hand. This corresponds to the findings published by [15]. The effect of orientation and build height show a similar severity.

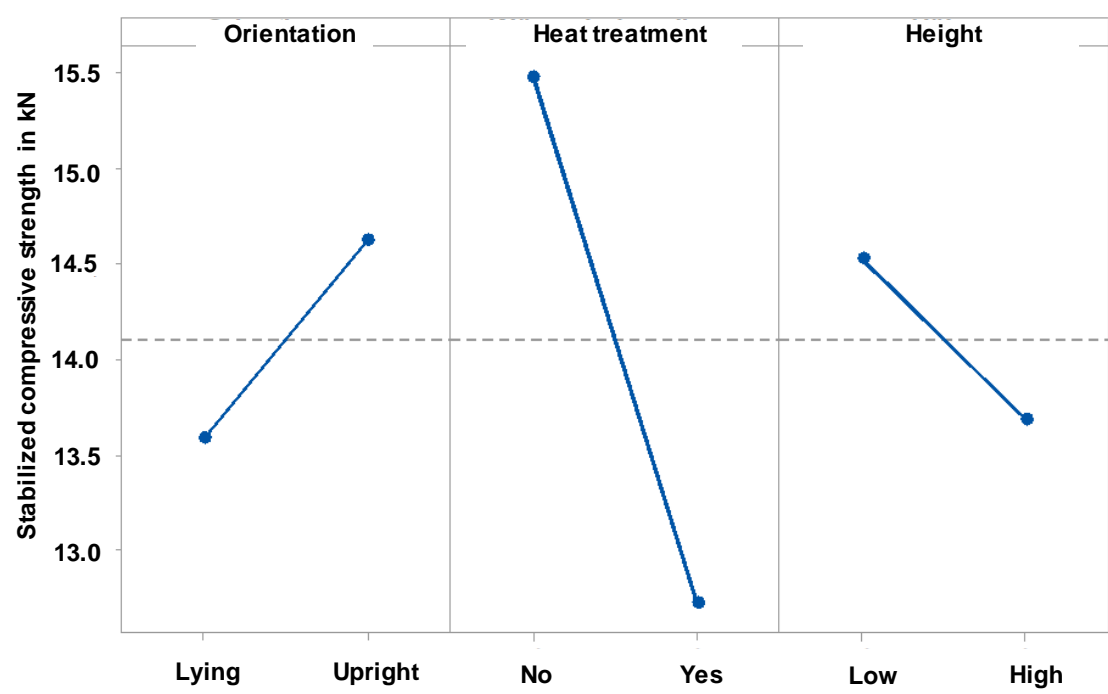

Figure 10: Main effects diagram for the compressive testing results of honeycombs manufactured by laser beam melting.

For the build orientation an effect has been expected. Honeycombs built in an upright position do not have overhang structures and are therefore less prone to manufacturing faults. Compared to the expected influence the measured effect of $7 \%$ loss in compressive strength is considered a minor effect.

As the failure of the honeycomb under compressive load is mainly comparable to buckling (Euler), the height could actually be of major relevance. For buckling modes, the length of the pole has a quadratic influence on the buckling force [16]. For the results at hand the height of the honeycombs has a measurable but not major influence.

Due to the use of DoE-methods the interactions between different input parameters can also be analyzed. The interactions can be seen in Figure 11.

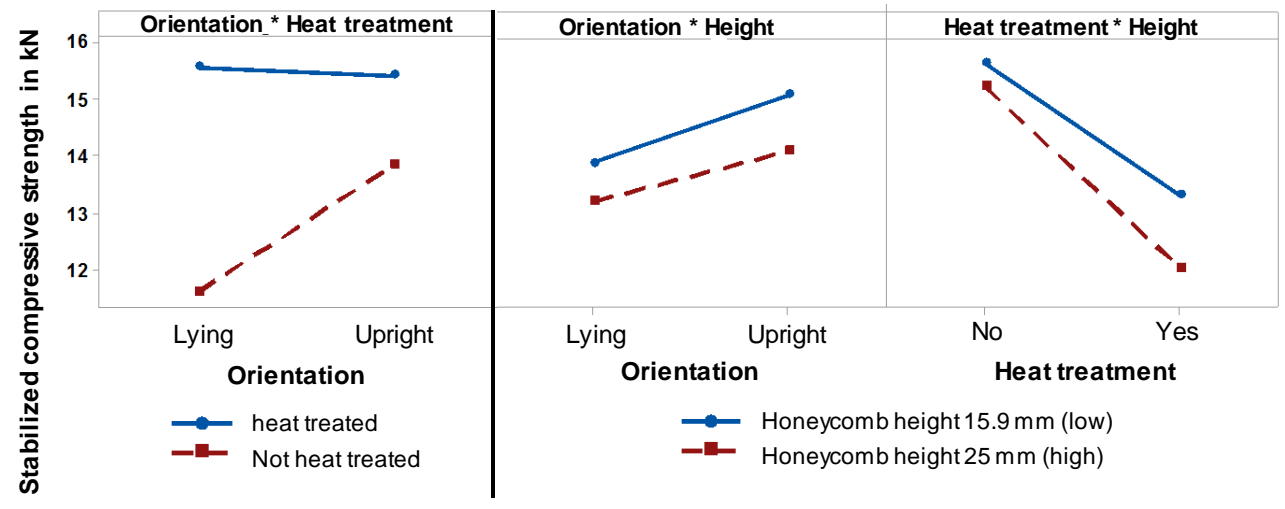

Figure 11: Interaction diagram for the compressive testing of honeycombs manufactured by laser beam melting.

While all other interactions seem to be minor or not visible a major interaction between the build orientation and the heat treatment can be seen in the diagrams. The loss in compressive strength due to the heat treatment is much more dominant for the horizontal honeycombs than for the upright ones. Two different effects explain this. On the one hand, the anisotropic behavior of the material generally 
leads to different strengths and elastic modulus. On the other hand, the overhang structures in the horizontal honeycombs may lead to holes or other flaws in the material structure, which are brought to light through the heat treatment.

\section{Discussion and conclusion}

The manufacturability of complexly shaped honeycomb structures by additive manufacturing methods (i.e. Laser Beam Melting LBM) has been successfully demonstrated. It could also be shown that honeycomb structures built from the alloy AISi10Mg can be built up to an overhang angle of $20^{\circ}$ without the need of support structures.

In a more detailed study the minimal reachable wall thickness of honeycombs manufactured by laser beam melting has been optimized. Values as low as $0.35 \mathrm{~mm}$ wall thickness could be reached.

The influence of the parameters build direction, heat treatment and build height onto the stabilized compressive strength were analyzed. This analysis leads to the conclusion that further investigations into the heat treatment of laser beam melted AISi10Mg will be of future interest. However, not only postprocess effects (heat treatment) were observed in this study. In addition, pre-process steps affect the minimal wall thickness that can be reached by utilizing laser beam melting. In particular, the scanning strategy foreseen by the software to prepare build job data needs to be well-understood, e.g. because of double scanning effects. In future work the manipulation of the build job software could be addressed to allow single exposure lines. By scanning a line just once the absorbed energy will bisect and thinner walls might be producible.

Generally, the relative compressive strength of LBM-built honeycomb structures is comparable to conventionally manufactured honeycomb structures, whereas the density of LBM-honeycomb structures is higher than the one of conventional honeycomb structures. As explained in this investigation the minimal wall thickness that could be obtained from the LBM-process is higher than that of conventional honeycomb core materials. Thus, LBM-manufactured honeycomb structures cannot instantly replace conventional core materials, but bring special benefits for applications that require a high load on a complexly shaped part, which needs to be light as well.

\section{References}

[1] Riss, F. et al.: Auslegung von Gitter- und Wabenstrukturen für die additive Fertigung. Lightweight Design 6 (2013), pp. 24-28.

[2] Riss, F. et al.: Load-dependent Optimization of Honeycombs for Sandwich Components - New Possibilities by Using Additive Layer Manufacturing, Physics Procedia, 2014, pp. 327-335.

[3] Rehme, O.: Cellular Design for Laser Freeform Fabrication, Cuvillier Verlag, Göttingen, 2010

[4] Bitzer, T.: Honeycomb Technology. Chapman \& Hall, 1997, S. 98-148

[5] EOS GmbH: Material data sheet EOS Aluminum AlSi10Mg. 2014

[6] 3A Composites GmbH: Alucore, 2017. http://media.alucobond.com/pdf/alucore/ALUCORE_TI_Prodlnfo_EN.pdf. (Accessed 13.05.2017)

[7] AmberComposites: Aac Amber Aluminium Commercial Honeycomb. http://www.jacomp.fi/wpcontent/uploads/2013/07/aac3003.pdf. (Accessed 13.05.2017).

[8] CEL Components S.r.l.: Aluminiumwabenkern Datenblatt, 2017. http://www.aluminiumwabe.com/img_ins/schede/alluminio-de.pdf. (Accessed 13.05.2017).

[9] Corex Honeycomb: Technical Spezifikation, 2017. http://corexhoneycomb.enco-cam.co.uk/wpcontent/uploads/sites/3/2016/10/Corex-Data-Sheet-160mm-fold-German-WEB.pdf. (Accessed 13.05.2017).

[10] Easy Composites: Technical Data Sheet. Product: Aluminium honeycomb core material, 04/2017. 
[11] Euro-Composites: Aluminium Honeycomb Core. Technical Data Sheet for all types, 2017. https://www.euro-composites.com/en/aluminium-wabe. (Accessed 13.05.2017).

[12] Lange+Ritter GmbH: Sandwichmaterialien Aluminiumwaben, 2017. Personal contact.

[13] Plascore GmbH \& CoKG: Aluminium Honeycomb, 2015. https://www.plascore.com/de/einangebot-an-produkten-von-weltrang/wabenkerne/aluminumwabenkerne. (Accessed 13.05.2017).

[14] Liu, $Q$ et al.: Crush response of CFRP square tube filled with aluminum honeycomb. Composites Engineering, 98 (2016), p. 406-414. doi:10.1016/j.compositesb.2016.05.048

[15] Rowolt, C. et al.: Laserstrahlgeschmolzene Bauteile - Wärmebehandlung optimiert Werkstoffeigenschaften. In: DVS Kongress 2017, Beitrags-Nr.: 5562.

[16] Läpple, V. (Hrsg.): Einführung in die Festigkeitslehre. Wiesbaden: Springer. 2016. ISBN 978-3658-10610-2 